patients who suffered acute ST was $20 \%$, compared to $80 \%$ following subacute ST. There was no difference in outcomes between bivalirudin treated patients who also received heparin compared to those who didn't (death $7.0 \%$ vs $5.0 \%$, p value: 0.80 ; MACE $14.0 \%$ vs $10.8 \%$, p value: 0.32 ; acute ST $0 \%$ vs $1.2 \%$, p: 0.61 ).

Abstract 29 Table 1 Outcomes at 30 days

\begin{tabular}{lcccc}
\hline & All patients & Bivalirudin & GPI + heparin & p value \\
\hline No. of patients & 968 & 882 & 85 & \\
Death & $52(5.4 \%)$ & $46(5.2 \%)$ & $6(7.1 \%)$ & 0.450 \\
Cardiac death & $45(4.7 \%)$ & $39(4.4 \%)$ & $6(7.1 \%)$ & 0.277 \\
Re-infarction & $16(1.7 \%)$ & $14(1.6 \%)$ & $2(2.4 \%)$ & 0.645 \\
Unplanned TVR & $12(1.2 \%)$ & $10(1.1 \%)$ & $2(2.4 \%)$ & 0.286 \\
Stroke & $56(5.8 \%)$ & $54(6.1 \%)$ & $2(2.4 \%)$ & 0.222 \\
Death, re-infarction, stroke or TVR & $110(11.4 \%)$ & $100(11.3 \%)$ & $10(11.8 \%)$ & 0.906 \\
Acute stent thrombosis & $10(1.0 \%)$ & $9(1.0 \%)$ & $1(1.2 \%)$ & 0.604 \\
Subacute stent thrombosis & $15(1.6 \%)$ & $13(1.5 \%)$ & $2(2.4 \%)$ & 0.386 \\
\hline
\end{tabular}

Conclusion Routine use of bivalirudin in a large UK all-comers primary PCI population was associated with excellent 30-day outcomes, including all-cause and cardiac mortality. Acute stent thrombosis was infrequent, despite the absence of routine additional heparin.

\section{COMPARISON OF BIVALIRUDIN VS ABCIXIMAB VS "UNFRACTIONATED HEPARIN ONLY" FOR PRIMARY PERCUTANEOUS CORONARY INTERVENTION IN A HIGH- VOLUME CENTRE}

doi:10.1136/heartjnl-2011-300198.30

R Showkathali, J Davies, N Malik, W Taggu, J Sayer, R Aggarwal, P Kelly. The Essex Cardiothoracic Centre, Basildon, UK

Introduction Primary percutaneous coronary intervention (PPCI) has been established as a standard therapy for ST elevation myocardial infarction (STEMI). In addition to thrombectomy and unfractionated heparin (UFH), thrombus burden in STEMI may require use of more potent antithrombotic agents. Bivalirudin is shown to be superior to abciximab in reducing the net adverse clinical events and major bleeding in STEMI in the HORIZONS-AMI trial (Stone et al NEJM, 2008). We aimed to carry out a "real world" comparison of different anti-thrombotic regimes in patients undergoing PPCI in our unit.

Methods Our PPCI service started in September 2009 and we included all patients undergoing PPCI between September 2009 and September 2010. Prospectively entered data were obtained from our dedicated cardiac service database system (Philips CVIS). Mortality data were obtained from the summary care record (SCR) database. We used Fisher's exact test to compare clinical outcomes between the groups.

Results Of the 998 patients admitted with suspected STEMI to our unit during the study period, 776 (77.8\%) underwent PPCI. After excluding patients who had both bivalirudin and abciximab during their procedure $(n=15)$, we divided the others $(n=761)$ into 3 groups according to the anti-thrombotic regime used (Grp 1- Abciximab +UFH, Grp 2- Bivairudin+UFH and Grp 3- "UFH only"). Patient demographics and procedural information are given in Abstract 30 table 1. Continuous data are presented as mean \pm SD. Clinical outcomes are shown in Abstract 30 table 2. In-hospital and 30-day mortality did not differ between patients who had bivalirudin vs abciximab $(5.6 \%$ vs $3.8 \%, p=0.35$ and $6.8 \%$ vs $5.2 \% p=0.53$ respectively). Both acute and 30 day stent thrombosis rates were also similar in the two groups $(0.6 \%$ vs none, $\mathrm{p}=0.3,0.6 \%$ vs $0.9 \%$, $p=1.0$ respectively). Even though the bleeding risk was higher in the abciximab group when compared with bivalirudin, this was not significant $(5.8 \%$ vs $3.1 \%, p=0.27)$. There was also no difference in the outcomes between the bivalirudin and "UFH only" groups for mortality, stent thromboses (acute and 30-day) and major bleeding. The abciximab group had significantly higher major bleeding rates than the "UFH only" group (5.8\% vs $2.4 \%, \mathrm{p}=0.04)$; all other outcomes were similar.

\section{Abstract 30 Table 1}

\begin{tabular}{llll}
\hline & $\begin{array}{l}\text { Abciximab }+ \\
\text { UFH (n=346) }\end{array}$ & $\begin{array}{l}\text { Bivalirudin }+ \\
\text { UFH (n=162) }\end{array}$ & $\begin{array}{l}\text { UFH only } \\
(\mathbf{n}=\mathbf{2 5 3})\end{array}$ \\
\hline Age in yrs (range) & $\begin{array}{l}\text { (n+14.1 } \\
(25-99)\end{array}$ & $65 \pm 13.0$ & $67 \pm 13.2$ \\
& 77.7 & 72.2 & $(30-96)$ \\
Male (\%) & 12.4 & 6.2 & 66.8 \\
Diabetes (\%) & 7.8 & 6.2 & 11.5 \\
Pre-procedure cardiogenic shock (\%) & 56.1 & 56.8 & 4.7 \\
Drug eluting stent (at least one) (\%) & $1.4 \pm 0.9$ & $1.4 \pm 0.8$ & 53.8 \\
No of stents & 91.3 & 87 & $1.4 \pm 0.9$ \\
Single vessel PCI (\%) & 1.4 & 1.9 & 89.3 \\
Three vessel PCI (\%) & 28 & 26.5 & 2 \\
Radial procedure (\%) & & & 31.2 \\
\hline
\end{tabular}

Abstract 30 Table 2

\begin{tabular}{|c|c|c|c|}
\hline$\%$ & $\begin{array}{l}\text { Abciximab }+ \\
\text { UFH }(n=346)\end{array}$ & $\begin{array}{l}\text { Bivalirudin }+ \\
\text { UFH }(n=162)\end{array}$ & $\begin{array}{l}\text { UFH only } \\
(n=253)\end{array}$ \\
\hline $\begin{array}{l}\text { In-hospital Mortality (including } \\
\text { cardiogenic shock) }\end{array}$ & 3.8 & 5.6 & 5.1 \\
\hline $\begin{array}{l}30 \text { day Mortality (including cardiogenic } \\
\text { shock) }\end{array}$ & 5.2 & 6.8 & 7.1 \\
\hline $\begin{array}{l}30 \text { day Mortality (excluding cardiogenic } \\
\text { shock) }\end{array}$ & 3.5 & 4.9 & 5.5 \\
\hline Stent Thrombosis (within 30 days) & 0.9 & 0.6 & 1.2 \\
\hline Acute stent Thrombosis $(24 \mathrm{~h}) \leq$ & 0 & 0.6 & 0.4 \\
\hline $\begin{array}{l}\text { Major bleed requiring blood transfusion } \\
\text { (non CABG related) }\end{array}$ & 5.8 & 3.1 & 2.4 \\
\hline $\begin{array}{l}\text { Access related bleed requiring } \\
\text { transfusion (includes IABP related) }\end{array}$ & 3.8 & 1.9 & 1.2 \\
\hline
\end{tabular}

Conclusion These "real-world" data do not show any significant difference in the clinical outcome for patients who had bivalirudin or abciximab. There was no advantage seen with the more expensive agent (abciximab) in keeping with previous trial data. Therefore bivalirudin should be considered as a non-inferior alternative to abciximab. This would have considerable economic benefits in the present situation. The "UFH only" group had similar outcomes to both bivalirudin and abciximab, which suggests that this may be a viable alternative in its own right. However, our study is clearly limited by not being randomised and those patients treated with UFH alone may have been a lower risk group.

\section{ASSESSMENT OF LEFT VENTRICULAR FUNCTION WITH CARDIAC MRI AFTER PERCUTANEOUS CORONARY INTERVENTION FOR CHRONIC TOTAL OCCLUSION}

doi:10.1136/heartjn|-2011-300198.31

${ }^{1} \mathrm{G}$ A Paul, ${ }^{2} \mathrm{~K}$ Connelly, ${ }^{1} \mathrm{~A}$ J Dick, ${ }^{1} \mathrm{~B}$ H Strauss, ${ }^{3} \mathrm{G}$ A Wright. ${ }^{1}$ Sunnybrook Health Sciences Centre, Toronto, Ontorio, Canada; ${ }^{2}$ St Michaels Hospital, Toronto, Ontorio, Canada: ${ }^{3}$ University of Toronto, Toronto, Ontorio, Canada

Objective To assess the role of CMR in the treatment of true chronic total occlusions (CTO) with percutaneous coronary intervention (PCI) and drug eluting stent implantation. 